Improved accuracy over established temperature-based models of estimating monthly average daily global solar irradiation by using ambient hourly temperature only

Keith De Souza

Citation: Journal of Renewable and Sustainable Energy 10, 043703 (2018); doi: 10.1063/1.5025474

View online: https://doi.org/10.1063/1.5025474

View Table of Contents: http://aip.scitation.org/toc/rse/10/4

Published by the American Institute of Physics 


\title{
Improved accuracy over established temperature-based models of estimating monthly average daily global solar irradiation by using ambient hourly temperature only
}

\author{
Keith De Souza \\ Center for Optoelectronics Research, Diego Martin, Trinidad and Tobago
}

(Received 9 February 2018; accepted 15 June 2018; published online 9 July 2018)

\begin{abstract}
A recently developed temperature-based model for predicting monthly average hourly global horizontal irradiation has been used to estimate monthly average daily global horizontal irradiation. In addition, a modified form of the HargreavesSamani model was implemented. Both models were evaluated alongside five existing temperature-based models due to Hargreaves and Samani, Allen, Bristow and Campbell, Goodin et al., and Hassan et al. for performance and applicability in Trinidad. Calibration and validation of the models were done using datasets of global horizontal irradiation and temperature from 2001-2005 and 2006-2010, respectively. The newly developed temperature-based model performed better than all other models. For an average year, yearly periods, and average and yearly periods collectively, the newly developed temperature-based model yielded root mean square errors of $0.51,0.86$, and $0.68 \mathrm{MJ} \mathrm{m}^{-2}$ day $^{-1}$, respectively, between the calculated and measured monthly average daily global horizontal irradiation. Similarly, the modified Hargreaves-Samani model was the next best performer with root mean square errors of $0.91,1.31$, and $1.11 \mathrm{MJ} \mathrm{m}^{-2} \mathrm{day}^{-1}$, respectively.
\end{abstract} Published by AIP Publishing. https://doi.org/10.1063/1.5025474

\section{INTRODUCTION}

Trinidad is an island of the twin-island state of the Republic of Trinidad and Tobago in the Caribbean, located between $61.93^{\circ} \mathrm{W}$ and $60.90^{\circ} \mathrm{W}$ longitude and $10.03^{\circ} \mathrm{N}$ and $10.85^{\circ} \mathrm{N}$ latitude, just off the northeast coast of Venezuela. Trinidad has an area of $4827 \mathrm{~km}^{2}$ while Tobago, the smaller of the two islands, has an area of $303 \mathrm{~km}^{2}$. The islands experience two seasonal climates due to their location, namely the Tropical Maritime or dry season, which occurs from January to May followed by the Modified Moist Equatorial or wet season, which occurs from June to December. The abundance of sunshine and hence global solar irradiation in Trinidad and Tobago facilitates the implementation of solar energy technologies, thereby reducing the use of fossil fuels for the generation of electricity and hence the country's carbon footprint.

Global solar irradiation data are used in many applications such as photovoltaic systems $(\mathrm{PV})^{1}$ design, solar thermal systems design, ${ }^{2}$ crop growth models, ${ }^{3}$ buildings design, ${ }^{4}$ and thermal comfort studies. ${ }^{5}$ Correlations between solar irradiation and meteorological variables can be used to estimate solar irradiation to fill missing datasets or to simulate solar irradiation where no such data ever existed but where climatological conditions are similar to the site of model development. De Souza and Andrews ${ }^{6}$ determined for the Caribbean island of Trinidad, Angström-Prescott models based on sunshine hours for different time scales. Recently, De Souza $^{7}$ developed a new empirical temperature-based model that calculates monthly average hourly global horizontal irradiation based on one input, ambient hourly temperature. For modeling of monthly average hourly global horizontal irradiation on both yearly and average year bases, the model yielded a root mean square error of $0.15 \mathrm{MJ} \mathrm{m}^{-2} \mathrm{~h}^{-1}$ between the calculated and measured monthly average hourly global horizontal irradiation and performed comparably to other well-established but more complex semi-empirical models. ${ }^{8-13}$ The monthly average 
hourly estimates for a typical day of every month can be summed to calculate monthly average daily global horizontal irradiation.

In the Caribbean, several weather stations in different islands do not measure and record global horizontal irradiation and sunshine-hours data but temperature data. Consequently, Angström-Prescott models cannot be calibrated and developed to estimate monthly average daily global horizontal irradiation. However, temperature-based models may provide a suitable alternative to estimate such global horizontal irradiation. Some of these models are now introduced. Hargreaves and Samani (HS) ${ }^{14}$ developed a non-linear model that predicts global horizontal irradiation using the difference in maximum and minimum temperatures and a single calibration coefficient. It has been used on average daily and monthly timescales. Bristow and Campbell $(\mathrm{BC})^{15}$ developed an exponential equation based on the difference in maximum and minimum temperatures and three empirical coefficients to predict global horizontal irradiation. It was derived for daily data but has been applied to monthly average data. Many derivatives of these models were developed by other researchers. For example, Annandale et al. ${ }^{16}$ modified the Hargreaves-Samani model by introducing an altitude-dependent factor. Allen (A) ${ }^{17}$ produced a self-calibrating model based on Hargreaves and Samani's model to calculate average monthly global horizontal irradiation. Goodin et al. $(\mathrm{G})^{18}$ modified Bristow and Campbell's model by introducing daily extra-terrestrial global horizontal irradiation in the model to act as a seasonal scaling factor. Recently, Hassan et al. $(\mathrm{H})^{19}$ developed seventeen temperature-based models to calculate monthly average daily global horizontal irradiation in various locations in Egypt. The best performing model was cited as model 6 which was based on monthly average daily ambient temperature. In the literature, the aforementioned models have been referred to as temperature-based models. This is true insofar as temperature is the only measured meteorological input required by these models. However, they are also dependent on solar irradiation input in the form of theoretically calculated daily extraterrestrial global horizontal irradiation, which itself requires astronomical factors (solar constant, solar declination angle, and sunset hour angle) and geographical factors (latitude and for the Annandale model, elevation).

In this paper, two temperature-based models to estimate monthly average daily global horizontal irradiation are developed. The first model is the De Souza model ${ }^{7}$ extended to calculate monthly average daily global horizontal irradiation. The second model is a derivative of the Hargreaves-Samani model. These models were evaluated alongside five existing temperaturebased models due to Hargreaves-Samani (HS) ${ }^{14}$ Allen (A), ${ }^{17}$ Bristow-Campbell (BC) ${ }^{15}$ Goodin et al. (G), ${ }^{18}$ and Hassan et al. (H). ${ }^{19}$ These five models were selected based on: (i) their widespread use, reported satisfactory performance and recent development and (ii) their different temperature inputs; monthly average daily temperature range, i.e., the difference between the extremes of daily temperatures are required for the $\mathrm{HS}, \mathrm{A}, \mathrm{BC}$, and $\mathrm{G}$ models while monthly average daily temperature is required by the $\mathrm{H}$ model. These two types of temperature inputs together with the hourly temperature input of the De Souza model allow a comparison of the performances of models covering three types of temperature inputs.

The main motivation for this work was to provide an empirical model that satisfactorily estimates monthly average daily global horizontal irradiation based on only one input; the meteorological input of hourly temperature and hence no dependence on solar irradiation whether ground-based or extraterrestrial, or any astronomical or geographical factors. The objectives of this paper are (i) to extend the De Souza $\operatorname{model}^{7}$ to estimate monthly average daily global horizontal irradiation; (ii) to formulate an Hargreaves-Samani type model; (iii) to evaluate and compare all seven models-those in (i) and (ii) and the five chosen existing temperature-based models - for applicability in Trinidad over an average year or long term using the five-year validation dataset; (iv) to evaluate the performance of the models over single years or short terms within the validation dataset; and (v) to propose the most suitable model for both yearly and average year application. Evaluation and comparisons were done graphically and statistically by comparing the calculated and measured monthly average daily global horizontal irradiation using mean bias error $(M B E)$, mean percentage error $(M P E)$, root mean square error $(R M S E)$, correlation coefficient $(r)$, and Nash-Sutcliffe efficiency (NSE). 
This study will contribute to the Caribbean basin and other territories having similar climate as Trinidad since monthly average daily global horizontal irradiation prediction would be possible wherever the required ambient temperature data is available. For such regions, the predicted monthly average daily global horizontal irradiation data can be used in initial feasibility studies and designing and implementing solar energy based technologies more efficiently and economically, ultimately reducing fossil fuel dependence and carbon footprint.

\section{THEORY}

The Hargreaves-Samani (HS), Allen (A), Bristow-Campbell (BC), and Goodin et al. (G) models have been used in a wide range of climatic conditions while the Hassan et al. $(\mathrm{H})$ model has been used in Egypt. This study would determine whether these models are weighted for or against the tropical climate of Trinidad. These five models are presented in Subsections II A-IIE in the following order: HS, A, BC, G, and H. For consistency and ease of reference throughout this paper, the two new models, which are presented in Subsections IIF and IIG, are referred to as the D1 and D2 models, where the former is the De Souza model ${ }^{7}$ extended to predict monthly average daily global horizontal irradiation and the latter is the modified Hargreaves-Samani type model. Subsection IIH addresses the statistical test parameters used to evaluate the performance of the models. In this paper, the models use monthly average daily values of all variables.

\section{A. The Hargreaves-Samani model (HS)}

The Hargreaves-Samani (HS) model is given by

$$
\bar{H}_{d}=\bar{H}_{o} a\left(T_{\max }-T_{\min }\right)^{1 / 2},
$$

where $\bar{H}_{d}$ is the monthly average daily global horizontal irradiation $\left(\mathrm{MJm}^{-2} \mathrm{day}^{-1}\right), \bar{H}_{0}$ is the monthly average daily extraterrestrial horizontal irradiation $\left(\mathrm{MJm}^{-2} \mathrm{day}^{-1}\right), a$ is the Hargreaves-Samani empirical coefficient $\left({ }^{\circ} \mathrm{C}^{-1 / 2}\right), T_{\max }$ is the measured monthly average daily maximum temperature $\left({ }^{\circ} \mathrm{C}\right)$, and $T_{\min }$ is the measured monthly average daily minimum temperature $\left({ }^{\circ} \mathrm{C}\right)$.

The daily extraterrestrial horizontal irradiation, $H_{o}$, in $\mathrm{Jm}^{-2}$ day ${ }^{-1}$, is given by (Duffie and Beckman $^{20}$ )

$$
H_{0}=\left(\frac{86400 I_{s c}}{\pi}\right)\left[\cos \varphi \cos \delta \sin \omega_{s}+\left(\frac{\pi \omega_{s}}{180}\right) \sin \varphi \sin \delta\right]\left[1+0.033 \cos \left(\frac{360 x}{365}\right)\right],
$$

where $I_{s c}$ is the solar constant $\left(1367 \mathrm{~W} / \mathrm{m}^{2}\right), \varphi$ is the latitude of the location, $\delta$ is the sun declination angle, and $\omega_{s}$ is the sunset hour angle, all expressed in degrees. The following equations define $\delta^{21}$ and $\omega_{s}^{22}$ as:

$$
\delta=23.45 \sin \left[360 \frac{(284+x)}{365}\right], \quad-23.45^{\circ} \leq \delta \leq 23.45^{\circ},
$$

where $x$ is the day of the year; for example, January 1st means that $x=1$ and

$$
\omega_{s}=\cos ^{-1}(-\tan \varphi \tan \delta) .
$$

\section{B. The Allen model (A)}

The Allen model is given by

$$
\bar{H}_{d}=\bar{H}_{o} a\left(T_{\max }-T_{\min }\right)^{b},
$$

where $a$ and $b$ are its empirical coefficients. 


\section{The Bristow-Campbell model (BC)}

The Bristow-Campbell (BC) model is an exponential model to determine average global horizontal irradiation and is given by

$$
\bar{H}_{d}=\bar{H}_{o} a\left[1-\exp \left(-b \Delta T^{\mathrm{c}}\right)\right]
$$

where $\Delta T$ is the monthly average daily temperature difference calculated from the daily temperature difference $\Delta T_{i}$ defined as

$$
\Delta T_{i}=T_{\max , i}-\frac{\left(T_{\min , i}+T_{\min , i+1}\right)}{2},
$$

where $a, b$, and $c$ are empirical coefficients, $T_{\max , i}$ is the measured average maximum temperature for the $i$ th day, $T_{\min , i}$ is the measured average minimum temperature for the $i$ th day, and $T_{\min , i+1}$ is the measured average minimum temperature for the $(i+1)$ th day.

$a$ represents the maximum clearness index obtained on a clear sky day and $\left[1-\exp \left(-b \Delta T^{c}\right)\right]$ represents the fraction of the maximum clearness index on a day with cover, determined by the coefficients, $b$ and $c$. Typical values for the Bristow-Campbell coefficients, $a, b$, and $c$ are 0.7, $0.004-0.010$, and 2.4, respectively, ${ }^{15}$ derived for and applicable to daily data and therefore are not necessarily optimum for monthly average daily data.

It should be noted that Eq. (7) represents a daily temperature range which accounts for the effects of advection. This temperature range differs from that used in the Hargreaves-Samani model in Eq. (1) which assumes no advection. In regions where advection is not an issue, $\Delta T$ in Eq. (6) can be replaced by $\Delta T=\left(T_{\max }-T_{\min }\right)$.

There is a physical significance to coefficient, $a$, which is related to the sum of the regression coefficients of the sunshine-based Angström-Prescott model ${ }^{23,24}$ which is defined as

$$
\frac{\bar{H}_{d}}{\overline{\bar{H}}_{o}}=p+q \frac{\bar{n}}{\bar{N}}
$$

where $\bar{N}$ is the theoretical monthly average number of sunshine hours per clear day, $\bar{n}$ is the measured monthly average number of sunshine hours per day for direct solar irradiation exceeding $120 \mathrm{Wm}^{-2}$, and $p$ and $q$ are regression coefficients. On clear sky days, when $\frac{\bar{n}}{\bar{N}}=1$, the maximum clearness index is $p+q$. Hence, $a=p+q$.

\section{The Goodin et al. model (G)}

The Goodin et al. model is given by

$$
\bar{H}_{d}=\bar{H}_{o} \mathrm{a}\left[1-\exp \left(-b \frac{\Delta T^{\mathrm{c}}}{\bar{H}_{o}}\right)\right],
$$

where $a, b$, and $c$ are its empirical coefficients.

\section{E. The Hassan et al. model (H)}

The best performing model in Egypt was model 6 given by

$$
\bar{H}_{d}=\bar{H}_{o}\left(a T_{\text {avg }}^{b} \bar{H}_{o}+c\right)
$$

where $a, b$, and $c$ are its empirical coefficients and $T_{\text {avg }}$ is the monthly average daily temperature. 


\section{F. The De Souza model (D1)}

The De Souza model ${ }^{7}$ is based on establishing for a typical day of any month, a pair of linear equations applicable to the day's morning and afternoon periods that relates monthly average hourly global horizontal irradiation to monthly average hourly normalized temperature (measured monthly average hourly temperatures divided by their corresponding monthly average daily temperature) using calibration datasets of the required variables. A typical day in a month is divided into morning and afternoon periods with respect to monthly average hourly global horizontal irradiation, for example, $6 \mathrm{~h}-11$ and $12 \mathrm{~h}-17 \mathrm{~h}$, respectively. ${ }^{7}$ For each month, the measured monthly average hourly global horizontal irradiation in the morning period, $6 \mathrm{~h}-11 \mathrm{~h}$, is regressed, in turn, against the measured monthly average hourly normalized temperature from 6 h- -11 h, 7 h- -12 h, 8 h- -13 h, and so on and the respective correlation coefficients are computed. Averages of the monthly correlation coefficients for each regression are calculated and the value closest to 1 is selected as the best regression result. A similar procedure is repeated for each month in the afternoon. Once the best regressions are determined then for each month of the year, four empirical coefficients-two for the morning $(a$ and $b)$ and two for the afternoon $(c$ and $d)$ are extracted.

In a previous study, ${ }^{7}$ the best regressions occurred between morning measured monthly average hourly global horizontal irradiation and measured monthly average hourly normalized temperature in the period $7 \mathrm{~h}-12 \mathrm{~h}$, and between afternoon measured monthly average hourly global horizontal irradiation and measured monthly average hourly normalized temperature in the period $15 \mathrm{~h}-20 \mathrm{~h}$.

Hence, the monthly average hourly global horizontal irradiation D1 model ${ }^{7}$ for a typical day of any month, is described by a pair of linear equations for the morning and afternoon periods, respectively given by

$$
\bar{H}_{m}=a \bar{T}_{m+1}-b
$$

and

$$
\bar{H}_{p}=c \bar{T}_{p+3}-d .
$$

Thus, the monthly average daily global horizontal irradiation is given by

$$
\bar{H}_{d}=\bar{H}_{m}+\bar{H}_{p},
$$

where $\bar{H}$ is the measured monthly average hourly global horizontal irradiation, $\bar{T}$ is the measured monthly average hourly normalized temperature, $m=6,7, \ldots ., 11$, where $m$ refers to morning hours $6 \mathrm{~h}-11 \mathrm{~h}$ local standard time and $p=12,13, \ldots \ldots 17$, where $p$ refers to afternoon hours $12 \mathrm{~h}-17 \mathrm{~h}$ local standard time.

Unlike the aforementioned models, the D1 model, after calibration, requires no input other than monthly average hourly normalized temperature data to calculate monthly average hourly global horizontal irradiation and then monthly average daily global horizontal irradiation.

\section{G. The modified Hargreaves-Samani model (D2)}

The modified Hargreaves-Samani model is given by

$$
\bar{H}_{d}=\bar{H}_{o} a\left(\frac{T_{\max }-T_{\min }}{T_{\text {avg }}}\right)^{b}
$$

where $a$ and $b$ are empirical coefficients.

\section{H. Statistical test parameters to evaluate and compare the models}

To determine how well measured and calculated monthly average daily global horizontal irradiation values agree with each other, i.e., to assess the predictive accuracy of the models, 
five statistical test parameters or performance indicators are considered in this analysis. These include $M B E\left(\mathrm{MJ} \mathrm{m}^{-2} \mathrm{day}^{-1}\right), M P E, R M S E\left(\mathrm{MJ} \mathrm{m}^{-2} \mathrm{day}^{-1}\right), r$, and NSE.

The following variables and statistical test parameters are defined as:

$\bar{H}_{i, c a l c}=i$ th calculated value of monthly average daily global horizontal irradiation,

$\bar{H}_{i, \text { meas }}=i$ th measured value of monthly average daily global horizontal irradiation,

$n=$ no. of values of $\left(\bar{H}_{i, \text { calc }}, \bar{H}_{i, \text { meas }}\right)$,

$i=1, \ldots, n$,

$\bar{H}_{\text {calc }}=$ average of $\bar{H}_{i, \text { calc }}$,

$\bar{H}_{\text {meas }}=$ average of $\bar{H}_{i, \text { meas }}$.

$$
\begin{aligned}
& M B E=\frac{1}{n} \sum_{i=1}^{n}\left(\bar{H}_{i, \text { calc }}-\bar{H}_{i, \text { meas }}\right), \\
& \operatorname{MPE}(\%)=\frac{1}{n} \sum_{i=1}^{n}\left(\frac{\bar{H}_{i, \text { calc }}-\bar{H}_{i, \text { meas }}}{\bar{H}_{i, \text { meas }}}\right) \times 100, \\
& R M S E=\left[\frac{1}{n} \sum_{i=1}^{n}\left(\bar{H}_{i, \text { calc }}-\bar{H}_{i, \text { meas }}\right)^{2}\right]^{1 / 2} \text {, } \\
& r=\frac{\sum_{\mathrm{i}=1}^{\mathrm{n}}\left(\bar{H}_{i, \text { meas }}-\bar{H}_{\text {meas }}\right)\left(\bar{H}_{i, \text { calc }}-\bar{H}_{\text {calc }}\right)}{\sqrt{\sum_{\mathrm{i}=1}^{\mathrm{n}}\left(\bar{H}_{i, \text { meas }}-\bar{H}_{\text {meas }}\right)^{2}} \sqrt{\sum_{\mathrm{i}=1}^{\mathrm{n}}\left(\bar{H}_{i, \text { calc }}-\bar{H}_{\text {calc }}\right)^{2}}}, \\
& N S E=1-\frac{\sum_{i=1}^{n}\left(\bar{H}_{i, \text { calc }}-\bar{H}_{i, \text { meas }}\right)^{2}}{\sum_{i=1}^{n}\left(\bar{H}_{i, \text { meas }}-\bar{H}_{\text {meas }}\right)^{2}}=1-\frac{n R M S E^{2}}{\sum_{i=1}^{n}\left(\bar{H}_{i, \text { meas }}-\bar{H}_{\text {meas }}\right)^{2}} .
\end{aligned}
$$

For better agreement between calculated and measured values, $M B E, M P E$, and $R M S E$ should simultaneously tend to zero while for greater correlation, $r$ is closer to 1 . The $M B E$ is a measure of systematic error and the long-term accuracy of the model and has an ideal value of 0 . For $M B E>0$ or $M B E<0$, on average, calculated values are overestimated or underestimated, respectively. An $M B E$ close to 0 can mean either that the calculated values are very good estimates of the measured values or that the sum of the positive deviations are almost nullified by the sum of the negative deviations leading to misinterpreted excellent model performance even though the calculated and measured values may not agree very closely. A similar explanation applies to the MPE, where in this case, the sum of the positive relative percentage errors can be almost cancelled by the sum of the negative relative percentage errors.

$R M S E$ is a measure of non-systematic error and the short-term accuracy of the model. RMSE $\geq 0$ and has an ideal value of 0 for perfectly matched calculated and measured values. It gives a good measure of the accuracy of the calculated values. The squared deviation between the calculated and measured values ameliorates the limitation of the $M B E$, but any large deviation between one or a few calculated-measured value pairs can lead to a significant increase in the RMSE value.

The correlation coefficient $r$ is a statistical measure of how the calculated and measured values vary in relation to each other and is defined as the ratio of the covariance to the product of the standard deviations of the measured and calculated values and ranges over $-1 \leq r \leq 1$. Greater correlation and anti-correlation between the calculated and measured values occur for $r$ closer to 1 and $r$ closer to -1 , respectively. 
The NSE is defined as one minus the sum of the squared differences between the calculated and measured values normalized by the variance of the measured values and ranges over $-\infty \leq N S E \leq 1$. For $N S E<0$, the mean of the measured data is a better predictor than the model; for $N S E=0$, the mean of the measured data is as good a predictor as the model; for $N S E>0$, the model is the better predictor and ideally for $N S E=1$, the model's predictions match the measured data perfectly.

\section{METHODOLOGY}

Data of measured hourly global horizontal irradiation and temperature for the years 2001-2010 were obtained from the Trinidad and Tobago Meteorological Services which is located at $10^{\circ} 35^{\prime} \mathrm{N}$ latitude, $61^{\circ} 21^{\prime} \mathrm{W}$ longitude, and $21.95 \mathrm{~m}$ above the mean sea level. A digital Eppley Black and White pyranometer, S/N 28370F3 with an hourly average uncertainty of $3 \%$ and a daily average uncertainty of $2 \%$ was used to measure hourly global horizontal irradiation. An Eppley integrator, S/N 412-10076 was used to log the global horizontal irradiation data. Temperatures were measured using dry bulb, wet bulb, maximum, and minimum thermometers located in a Stevenson screen $1.2 \mathrm{~m}-2 \mathrm{~m}$ above the ground. The dry bulb, wet bulb, and maximum thermometers were mercury in glass double sheathed while the minimum thermometer was alcohol in glass, all made by Cassella UK, Ltd., and conforming to British Standard 692. The measurement uncertainty of the thermometers was $\pm 0.05^{\circ} \mathrm{C}$. Hourly temperatures were manually recorded. The Trinidad and Tobago Meteorological Services, as a member of the World Meteorological Organization, follows the organization's standards and best practices with respect to maintenance and calibration of its instruments.

The ten-year hourly global horizontal irradiation dataset 2001-2010 comprising 39788 data points were subjected to quality control as outlined in De Souza. ${ }^{7}$ Hourly and daily maximum and minimum temperature datasets were complete.

\section{A. Temperature profiles and advection}

Ten-year monthly averages of daily ambient temperature, maximum temperature and minimum temperature were computed and their monthly variation plotted on a graph. Computations with the ten-year temperature data were performed to compare $\left(T_{\max }-T_{\min }\right)$ and $\Delta T$ as defined in Subsections II A and IIC, respectively, to determine whether advection was of any consequence.

\section{B. Empirical coefficients of the seven models}

The D1 model was used to calculate monthly average daily global horizontal irradiation and as such utilized the empirical coefficients previously obtained therein. ${ }^{7}$ For the other six models in this study, the ten-year global horizontal irradiation and temperature datasets were divided into calibration datasets 2001-2005 and validation datasets 2006-2010. For the global horizontal irradiation calibration dataset, the total number of measured hourly global horizontal irradiation data points was 21010 and the corresponding number of data points for the validation dataset was 18 778. From the calibration dataset, five-year monthly average daily global horizontal irradiation was calculated. From the complete temperature calibration datasets, fiveyear monthly averages of daily, minimum, and maximum ambient temperatures were calculated.

The calibration datasets were used to determine the local empirical coefficients of the D2, HS, A, BC, G, and H models. The empirical coefficients were determined as those which minimized the residual sum of squares between calculated and measured monthly average daily global horizontal irradiation. In accordance with Subsection IIC which provided the theory for the $\mathrm{BC}$ model, its empirical coefficient, $a$, was determined to be 0.59 which is the sum of the Angström-Prescott empirical coefficients which were previously determined for Trinidad. ${ }^{6}$ Its two other coefficients were determined using the residual sum of squares technique. For all the 
models, different initial values of empirical coefficients were used to ensure repeatable convergence to the residual sum of squares values.

\section{Evaluation and performance of the models}

Six validation periods were established from the validation dataset: a five-year period 2006-2010 and five one-year periods-2006, 2007, 2008, 2009, and 2010. The performance of the seven models in these periods was assessed through calculated statistical test parameters and suitable graphs offering different perspectives.

For an average year of the five-year validation period 2006-2010, the calculated values of monthly average daily global horizontal irradiation from all seven models and the measured monthly average daily global horizontal irradiation were used to calculate the models' five statistical test parameters. In addition, seven graphs showing the monthly variation of calculated and measured monthly average daily global horizontal irradiation for the seven models were produced.

Similar to the procedure for an average year, for each of the five yearly validation periods, the five statistical test parameters were determined for the seven models. Seven graphs showing the monthly variation of calculated and measured monthly average daily global horizontal irradiation over the sixty months that constitute the five years, 2006 to 2010, were produced for the seven models.

By considering the five yearly periods collectively, the monthly performance of the models was determined by calculating monthly root mean square errors. The performance of the models in the short term was analyzed using statistical test parameters and scatter plots of calculated versus measured monthly average daily global horizontal irradiation and 1:1 lines. The best performing model in the yearly short term was determined. Finally, the model best suited for application on both yearly and average year bases was determined.

\section{RESULTS AND DISCUSSION}

Subsection IV A presents the monthly variation of monthly averages of daily ambient temperature, maximum temperature and minimum temperature, and advection is dealt with. The empirical coefficients of all models are given in Subsection IV B. Subsection IV C commences by displaying the hourly performance of the $\mathrm{D} 1 \operatorname{model}^{7}$ before evaluating the performance of the models over the six validation periods.

\section{A. Temperature profiles and advection}

Figure 1 shows the monthly variation of the ten-year monthly averages of daily ambient temperature, maximum temperature, and minimum temperature over the period 2001-2010. The maximum temperature ranged from $31.07^{\circ} \mathrm{C}$ in January to $32.95^{\circ} \mathrm{C}$ in April. It increased from January to April, decreased to $31.82{ }^{\circ} \mathrm{C}$ in June, increased to $33.18{ }^{\circ} \mathrm{C}$ in September, and decreased for the next three months to $31.27^{\circ} \mathrm{C}$ in December. The average temperature ranged from $25.86^{\circ} \mathrm{C}$ in January to $27.88^{\circ} \mathrm{C}$ in May. It increased from January to May, decreased to $27.20^{\circ} \mathrm{C}$ in July, increased to $27.61{ }^{\circ} \mathrm{C}$ in September, and decreased for the next three months to $26.14{ }^{\circ} \mathrm{C}$ in December. The minimum temperature ranged from $21.96{ }^{\circ} \mathrm{C}$ in February to $24.52^{\circ} \mathrm{C}$ in May. After decreasing from January to February, it increased from February to May, decreased to $24.00{ }^{\circ} \mathrm{C}$ in August, increased to $24.03^{\circ} \mathrm{C}$ in September, and decreased for the next three months to $22.81^{\circ} \mathrm{C}$ in December. The peak that occurs in September during the wet season (June to December), in all three plots, is a period during the rainy season called "petit carême" where there is an increase in the number of sunshine hours, and decreases in cloud cover, humidity, and rainfall.

Figure 2 shows a scatter plot of $\Delta T$ against $\left(T_{\max }-T_{\min }\right)$ and a 1:1 line for the ten-year period 2001-2010. It is evident that $\Delta T \sim T_{\max }-T_{\min }$ and thus advection is not a factor in Trinidad which confirms the statement by Castellvi, ${ }^{25}$ that for sites in tropical latitudes, the 


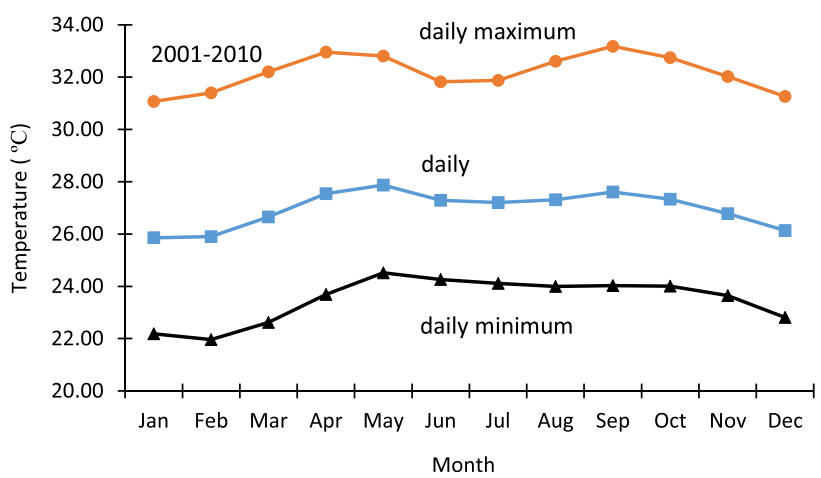

FIG. 1. Plots of monthly variation of the ten-year monthly averages of daily ambient temperature, maximum temperature, and minimum temperature over the period 2001-2010.

correction offered by $\Delta T$ is often unnecessary. Consequently, in Eq. (6), $\Delta T$ can be replaced by $\left(T_{\max }-T_{\min }\right)$.

\section{B. Empirical coefficients of the seven models}

The four empirical coefficients for the monthly average hourly global horizontal irradiation D1 model identified in Eqs. (11) and (12) were previously determined by De Souza ${ }^{7}$ and are given in Table I. The empirical coefficients for the remaining six models: D2, HS, A, BC, G, and $\mathrm{H}$ are provided in Table II. The location-specific value of the empirical coefficient for the HS model is comparable to the value of 0.16 recommended by Hargreaves ${ }^{26}$ for interior regions.

\section{Evaluation and performance of the models}

The reported good performance of the D1 model ${ }^{7}$ on an hourly time scale is provided by Fig. 3 which shows the variation of the calculated and measured monthly average hourly global solar irradiation with solar time for all months in an average year of the validation period 2006-2010. Previously reported values of RMSE $\left(\mathrm{MJ} \mathrm{m}^{-2} \mathrm{~h}^{-1}\right.$ ) between the calculated and measured irradiation are also given with a range of $0.08-0.151 \mathrm{MJ} \mathrm{m}^{-2} \mathrm{~h}^{-1}$.

For the current study, the criterion for the selection of best performing models based on statistical test parameters is as follows: provided that all calculated statistical test parameters are acceptable, the model with the lowest value of RMSE is the best performing model.

Table III shows the calculated statistical test parameters for the seven monthly average daily global horizontal irradiation models applied to a typical day in all the validation periods, namely the five-year period 2006-2010 and each single year therein.

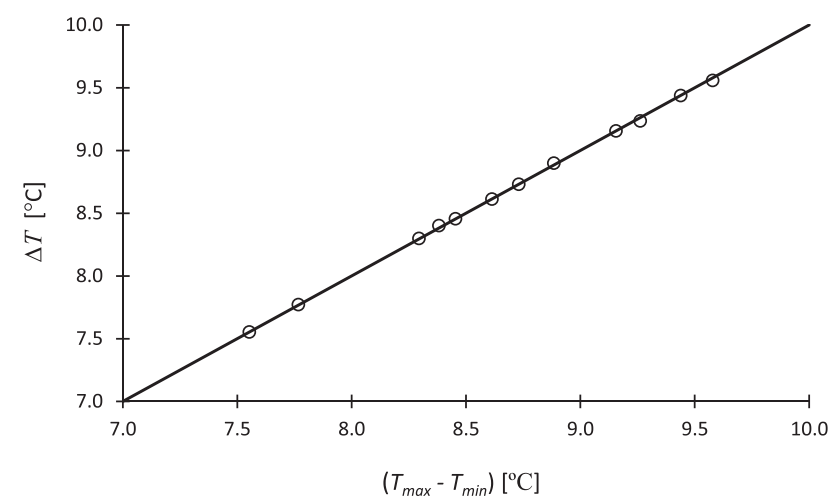

FIG. 2. 1:1 line and scatter plot of monthly average daily values of $\Delta T$ versus $\left(T_{\max }-T_{\min }\right)$ for a ten-year period 2001-2010. 
TABLE I. Empirical coefficients $a, b, c$, and $d$ for the twelve monthly average hourly D1 models using calibration datasets from the period 2001-2005.

\begin{tabular}{lcccc}
\hline \hline Month & $a$ & $b$ & $c$ & $d$ \\
\hline Jan & 7.42 & 6.28 & 12.53 & 12.17 \\
Feb & 7.43 & 6.15 & 12.37 & 12.00 \\
Mar & 7.88 & 6.53 & 12.54 & 12.09 \\
Apr & 8.22 & 6.92 & 13.17 & 12.63 \\
May & 9.84 & 8.68 & 14.28 & 13.74 \\
Jun & 10.02 & 8.89 & 15.25 & 14.81 \\
Jul & 9.18 & 6.90 & 14.76 & 14.36 \\
Aug & 8.06 & 6.09 & 14.10 & 13.74 \\
Sept & 7.26 & 6.66 & 14.00 & 13.68 \\
Oct & 7.80 & 7.02 & 15.07 & 14.74 \\
Nov & 8.04 & 6.28 & 13.34 & 13.01 \\
Dec & 7.29 & $6.09-8.89$ & 11.96 & 11.67 \\
Range & $7.26-10.02$ & & $11.96-15.25$ & $11.67-14.81$ \\
\hline \hline
\end{tabular}

\section{An average year}

Table III shows that for an average year of the five-year validation period 2006-2010, $M B E$ ranged from -0.20 to $-0.03 \mathrm{MJ} \mathrm{m}^{-2}$ day $^{-1}$; MPE ranged from -1.03 to $0.21 ; R M S E$ ranged from 0.51 to $0.97 \mathrm{MJ} \mathrm{m}^{-2}$ day $^{-1} ; r$ ranged from 0.68 to 0.94 , and NSE ranged from 0.46 to 0.85 . All the models had acceptable values of MBE, MPE, and RMSE. The D1 model showed the strongest correlation of 0.94. In terms of RMSE, the D1 model performed the best with an $R M S E$ of $0.51 \mathrm{MJ} \mathrm{m}^{-2}$ day $^{-1}$ followed by the D2 model with an RMSE of $0.91 \mathrm{MJ}$ $\mathrm{m}^{-2}$ day $^{-1}$.

Figure 4 shows the monthly variation of the calculated and measured monthly average daily global horizontal irradiation for the seven models for an average year in the five-year validation period 2006-2010. It is clear, that for an average year, the D1 model shows superior performance as corroborated by its RMSE and tracks the measured solar irradiation $(r=0.94)$ much better than the other models over the dry (January to May) and wet (June to December) seasons. Hence, it is valid under both clear sky and cloudy conditions. It underestimates November and December more than other similar months but by only 0.8 and $0.7 \mathrm{MJ}$ $\mathrm{m}^{-2}$ day $^{-1}$, respectively. The A and D2 models are derivatives of the HS model. The A and HS models show similar performances with the A model's estimations more closely matching the measured data for the first four months of the average year. The D2 model's estimations match those same four months with a better overall performance. The D2 model also estimates most closely the three coolest months of the year which are January, November, and December, with January occurring in the dry season and the latter two months occurring in the wet season. The

TABLE II. Empirical coefficients for the six models to estimate monthly average daily global horizontal irradiation obtained using calibration datasets from the period 2001-2005.

\begin{tabular}{lccc}
\hline \hline Model & $\mathrm{a}$ & $\mathrm{b}$ & $\mathrm{c}$ \\
\hline $\mathrm{D} 2$ & 0.8917 & 0.6059 & \\
$\mathrm{HS}$ & 0.1522 & & \\
$\mathrm{~A}$ & 0.1153 & 0.6287 & 1.2759 \\
$\mathrm{BC}$ & 0.5900 & 0.0878 & 1.1530 \\
$\mathrm{G}$ & 0.6000 & -4.0839 & 0.5548 \\
$\mathrm{H}$ & $2.98 \times 10^{-6}$ & 2.1019 & \\
\hline \hline
\end{tabular}



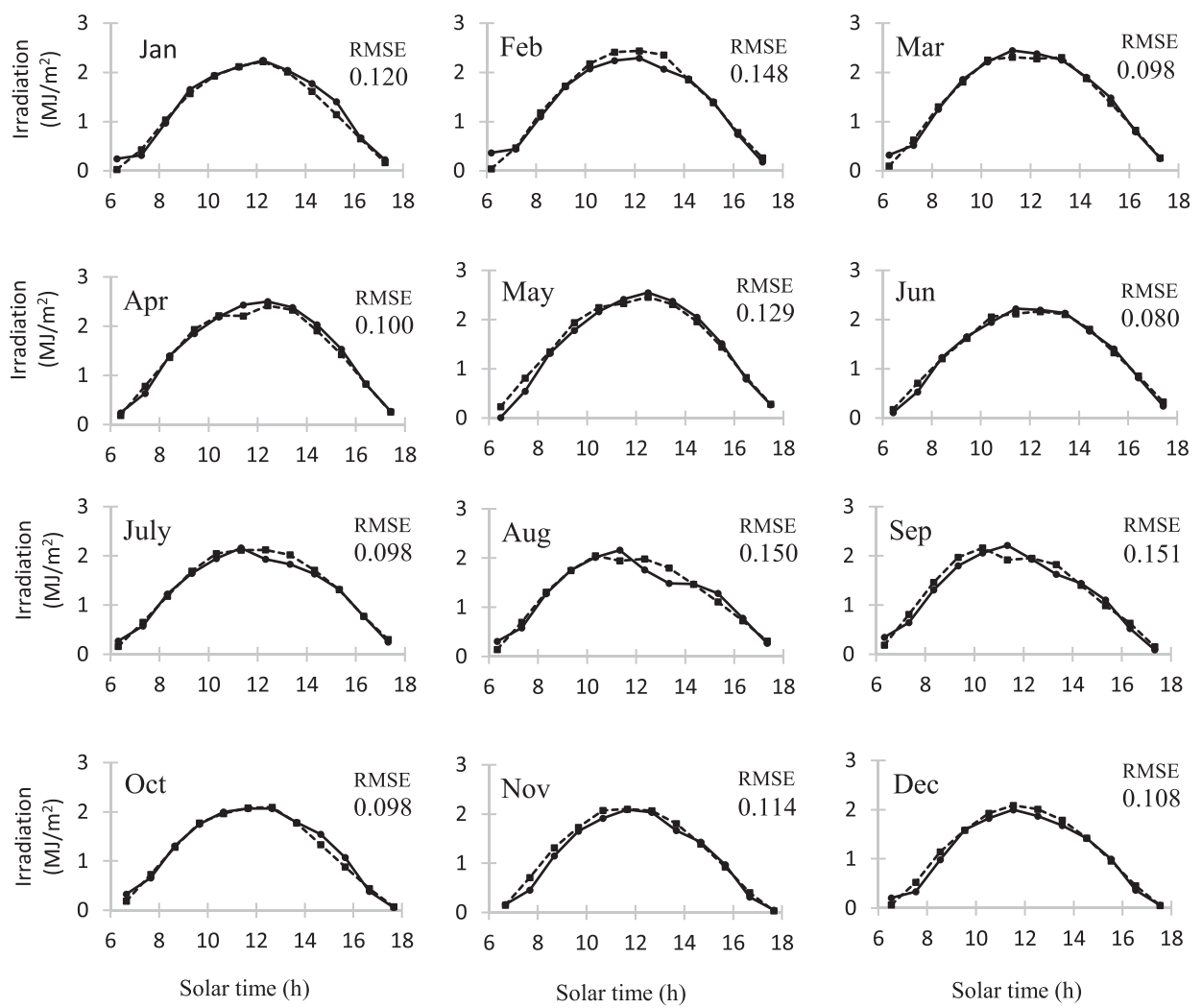

FIG. 3. Graphs of calculated (solid line) and measured (dashed line) monthly average hourly global solar irradiation against solar time (h) for the D1 model for all months of an average year in the validation period 2006-2010.

$\mathrm{BC}$ and $\mathrm{G}$ models perform similar to the A model. The $\mathrm{H}$ model performs worse than the other six models over the dry season (January to May) but better than all models except the D1 model over the wet season (June to December).

Hence, for an average year, the D1 model was the top performer followed by the D2 model.

\section{The five yearly validation periods}

The performance of the models over the yearly validation periods from 2006 to 2010 will be analyzed using the calculated values of statistical test parameters in Table III and plots given in Figs. 5-7.

Figure 5 are column graphs showing the variation of the five statistical test parameters for all seven models for the years 2006 to 2010 using the data from Table III. The graphs effectively allow the models' statistical test parameters to be compared visually every year. For example, focusing on the RMSE graph and the D1 model, the column is composed of five segments representing RMSE values for five years, starting at the bottom with 2006 and ending at the top with 2010. The shorter the segments, the better the yearly performances. The height of the column is the sum of the five RMSEs and thus the lower the height, the better the performance of the model over the five years. Comparing the H and D1 models for instance, it is clear that for four years $(2006,2007,2008$, and 2010), the D1 model performs better than the $\mathrm{H}$ model and for 2009, they perform comparably. It is also evident that over the five years, the D1 model significantly distinguishes itself from the six other models all of which show comparable performance with one another. For the remaining four graphs, similar inspections can be done where shorter segments and column heights for $M B E$ and $M P E$ mean better model performance while longer segments and column heights for $r$ and NSE mean better performance. The 
TABLE III. Statistical test parameters for each of the seven monthly average daily global horizontal irradiation models applied to the six validation periods. $M B E$ and $R M S E$ have units of $\mathrm{MJ} \mathrm{m}^{-2}$ day $^{-1}$. The lowest value of $R M S E$ in each validation period is emboldened and the best performing model given.

\begin{tabular}{|c|c|c|c|c|c|c|c|c|c|}
\hline Validation period & Statistical test parameters & HS & $\mathrm{A}$ & $\mathrm{BC}$ & G & $\mathrm{H}$ & D1 & D2 & Best model \\
\hline \multirow[t]{5}{*}{ 2006-2010 } & $M B E$ & -0.09 & -0.07 & -0.06 & -0.03 & -0.20 & -0.16 & -0.07 & \multirow{5}{*}{ D1 } \\
\hline & $M P E$ & -0.35 & -0.24 & -0.15 & 0.21 & -0.86 & -1.03 & -0.23 & \\
\hline & RMSE & 0.94 & 0.97 & 0.97 & 0.97 & 0.97 & 0.51 & 0.91 & \\
\hline & $r$ & 0.73 & 0.73 & 0.72 & 0.68 & 0.71 & 0.94 & 0.74 & \\
\hline & $N S E$ & 0.49 & 0.46 & 0.47 & 0.46 & 0.46 & 0.85 & 0.53 & \\
\hline \multirow[t]{5}{*}{2006} & $M B E$ & -0.07 & -0.10 & -0.10 & -0.04 & 0.10 & 0.11 & 0.003 & \multirow{5}{*}{ D2 } \\
\hline & $M P E$ & -0.08 & -0.36 & -0.31 & 0.37 & 1.56 & 0.97 & 0.40 & \\
\hline & RMSE & 0.93 & 0.90 & 0.90 & 0.99 & 1.36 & 0.90 & 0.83 & \\
\hline & $r$ & 0.85 & 0.87 & 0.86 & 0.87 & 0.71 & 0.87 & 0.89 & \\
\hline & $N S E$ & 0.73 & 0.74 & 0.74 & 0.69 & 0.41 & 0.74 & 0.78 & \\
\hline \multirow[t]{5}{*}{2007} & $M B E$ & -0.47 & -0.46 & -0.45 & -0.42 & -0.47 & -0.49 & -0.34 & \multirow{5}{*}{ D1 } \\
\hline & $M P E$ & -2.32 & -2.27 & -2.22 & -1.82 & -1.97 & -2.87 & -1.46 & \\
\hline & $R M S E$ & 1.34 & 1.31 & 1.33 & 1.38 & 1.61 & 0.76 & 1.32 & \\
\hline & $r$ & 0.71 & 0.72 & 0.71 & 0.70 & 0.51 & 0.95 & 0.70 & \\
\hline & $N S E$ & 0.43 & 0.46 & 0.44 & 0.39 & 0.18 & 0.82 & 0.45 & \\
\hline \multirow[t]{5}{*}{2008} & $M B E$ & -0.12 & -0.07 & -0.07 & -0.21 & -0.37 & -0.13 & -0.05 & \multirow{5}{*}{ D1 } \\
\hline & $M P E$ & -0.13 & 0.12 & 0.14 & -0.65 & -1.68 & -0.65 & 0.24 & \\
\hline & RMSE & 1.45 & 1.48 & 1.47 & 1.39 & 1.33 & 0.52 & 1.34 & \\
\hline & $r$ & 0.26 & 0.26 & 0.26 & 0.23 & 0.34 & 0.93 & 0.35 & \\
\hline & NSE & -0.14 & -0.19 & -0.17 & -0.06 & 0.04 & 0.85 & 0.03 & \\
\hline \multirow[t]{5}{*}{2009} & $M B E$ & -0.54 & -0.58 & -0.56 & 0.50 & -0.47 & -0.39 & -0.64 & \multirow{5}{*}{ D1 } \\
\hline & $M P E$ & -3.04 & -3.30 & -3.17 & 2.59 & -2.41 & -2.14 & -3.61 & \\
\hline & RMSE & 1.17 & 1.24 & 1.22 & 1.23 & 1.17 & 1.16 & 1.30 & \\
\hline & $r$ & 0.72 & 0.71 & 0.70 & 0.63 & 0.69 & 0.72 & 0.67 & \\
\hline & $N S E$ & 0.35 & 0.27 & 0.29 & 0.28 & 0.35 & 0.36 & 0.20 & \\
\hline \multirow[t]{5}{*}{2010} & $M B E$ & 0.83 & 0.99 & 0.92 & 0.96 & 0.06 & 0.31 & 0.76 & \multirow{5}{*}{ D1 } \\
\hline & $M P E$ & 6.25 & 7.21 & 6.81 & 7.29 & 1.72 & 2.20 & 5.87 & \\
\hline & RMSE & 1.75 & 1.82 & 1.81 & 1.76 & 1.79 & 0.76 & 1.72 & \\
\hline & $r$ & 0.59 & 0.62 & 0.60 & 0.63 & 0.32 & 0.93 & 0.59 & \\
\hline & $N S E$ & 0.13 & 0.07 & 0.08 & 0.12 & 0.10 & 0.84 & 0.17 & \\
\hline
\end{tabular}

D1 model again distinguishes itself from the others with respect to $r$ and NSE. In terms of $N S E$, only the D1, D2, and $\mathrm{H}$ models were better predictors of monthly average daily horizontal irradiation for each year $(N S E>0)$ than the mean of the measured data. The MBE graph shows that all the models at times overestimated and underestimated the monthly average daily global horizontal irradiation and along with the MPE graph show the comparatively better performance of the D1 model.

Figure 6 shows the monthly variation of calculated and measured monthly average daily global horizontal irradiation of the D1, D2, HS, and A models over the sixty months that constitute the five years, 2006 to 2010. Figure 7 shows similar graphs for the BC, G, and $\mathrm{H}$ models. Focusing on the D1 model, the measured monthly average daily global horizontal irradiation varies from year to year as can be expected. The last two months, November and December of 2008, had no available irradiation data and hence the missing points in the 35th and 36th months. A similar situation occurred for the months of June and Julymonths 54 and 55-in the year 2010. Obviously, these yearly variations of measured monthly average daily global horizontal irradiation are the same for all the models in Figs. 6 and 7. 

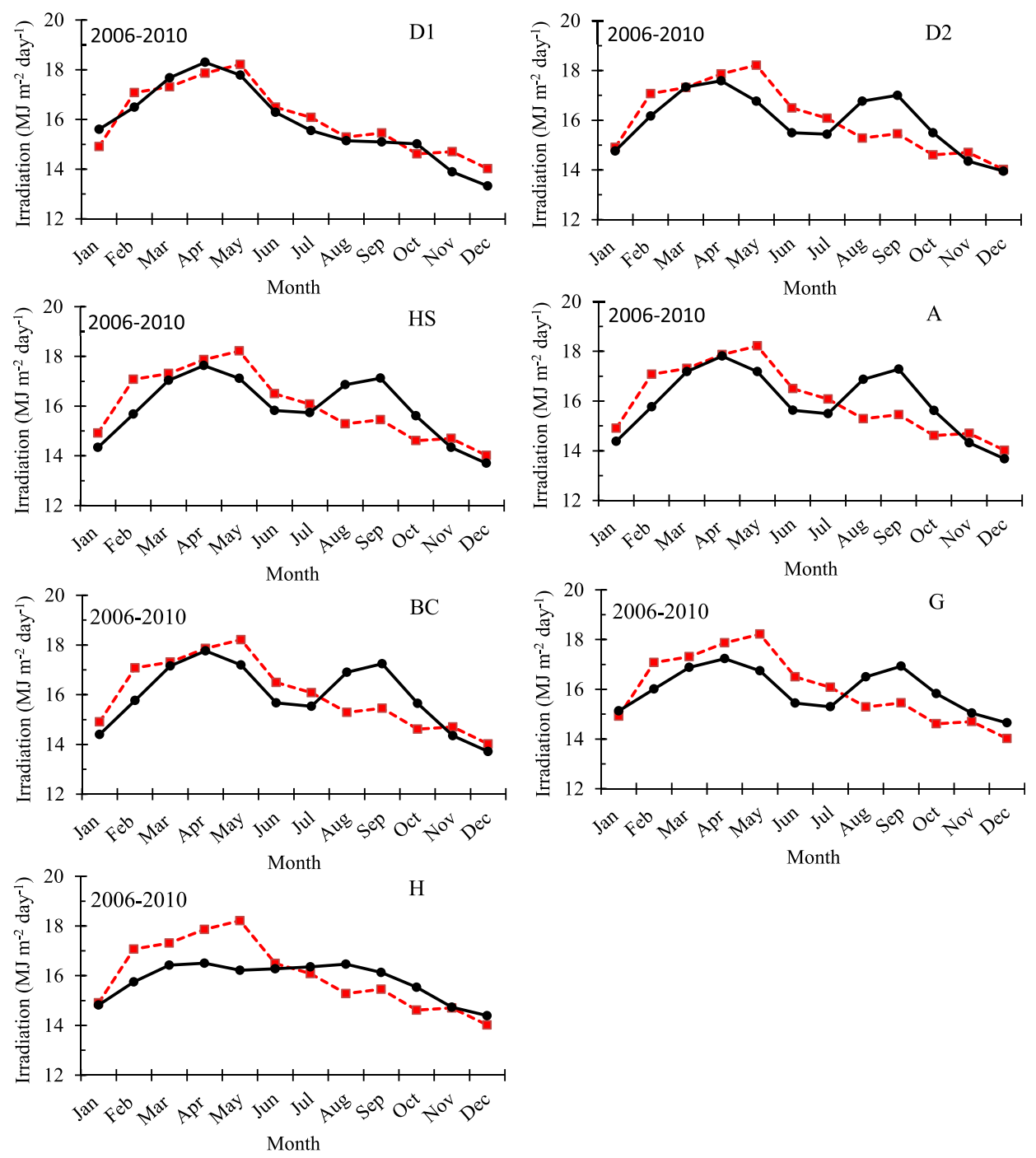

FIG. 4. Graphs of monthly variation of calculated (solid line) and measured (dashed line) monthly average daily global solar irradiation for the D1, D2, HS, A, BC, G, and H models for an average year in the validation period 2006-2010.

For the validation year 2006, the models yielded acceptable values of statistical test parameters. The HS, A, BC, and G models underestimated $(\mathrm{MBE}<0)$ while the $\mathrm{H}, \mathrm{D} 1$, and $\mathrm{D} 2$ models overestimated $(\mathrm{MBE}>0)$ the monthly average daily global horizontal irradiation. The D2 model was the best performing model with an RMSE of $0.83 \mathrm{MJ} \mathrm{m}^{-2}$ day $^{-1}$ followed collectively by the D1, A, and BC models (Fig. 5). Figures 6 and 7 corroborate the analysis for the year 2006.

For the validation year 2007, the models yielded acceptable values of statistical test parameters. All the models, on average, underestimated the monthly average daily global horizontal irradiation. The D1 model performed best with an RMSE of $0.76 \mathrm{MJ} \mathrm{m}^{-2} \mathrm{day}^{-1}$ followed by close agreement between the A, D2, BC, HS, and G models (see Fig. 5). The H model performed the worst. Figures 6 and 7 corroborate the analysis for the year 2007 and the superior performance of the D1 model is evident. The calculated and measured plots show better correlation and they are closer to each other as compared to the corresponding plots of the other six models. The plots of D1 and D2 also illustrate a limitation of the $M B E$ alluded to in Subsection II H. The better $M B E$ of D2 is due to its total overestimation being more closely counter-balanced by its total underestimation but clearly, as shown in Fig. 6, D1 performs better than D2. 

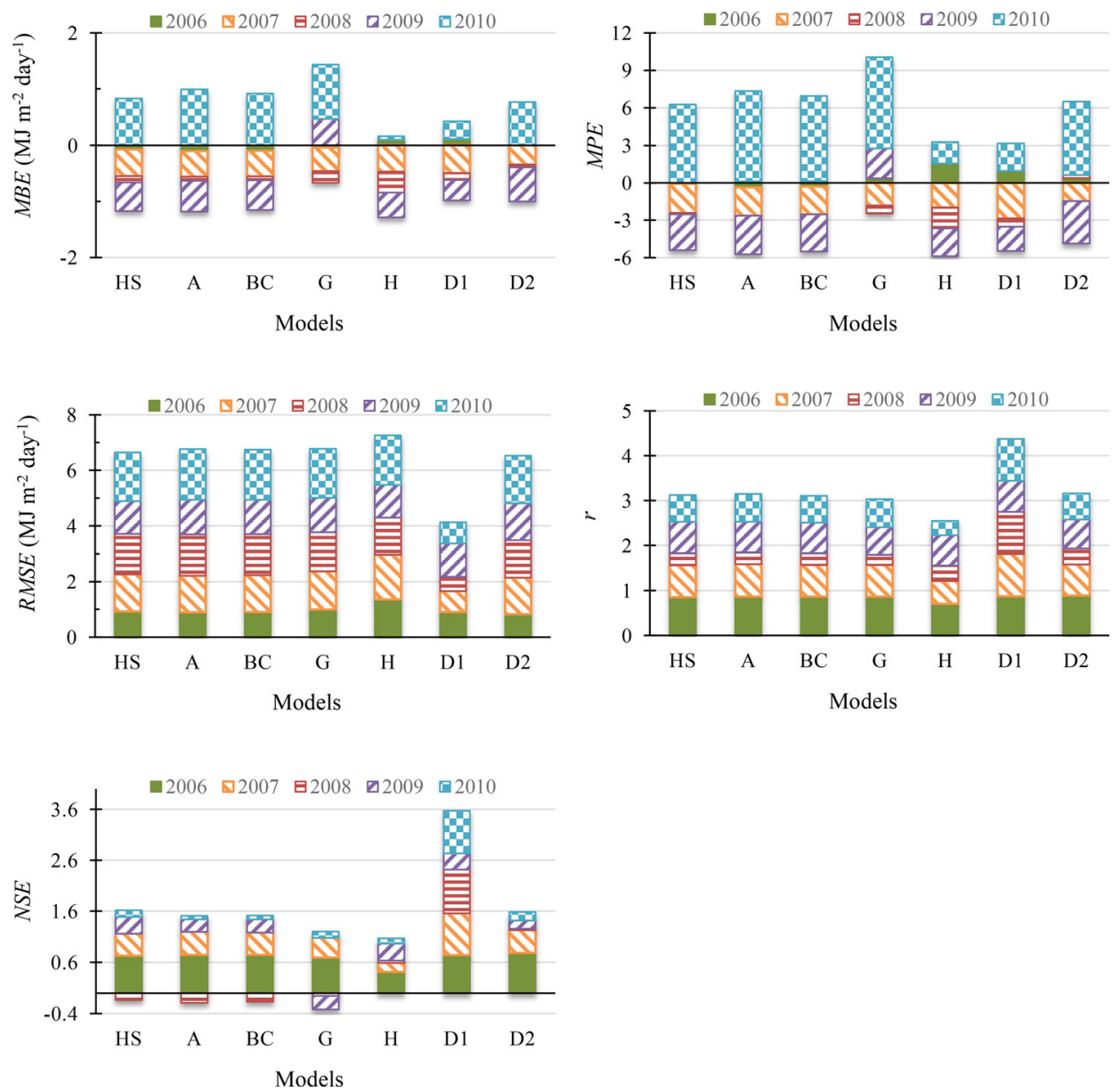

FIG. 5. Column graphs showing the variation of the five statistical test parameters for all seven models for the years 2006-2010.

For the validation year 2008, all the models, on average, underestimated the monthly average daily global horizontal irradiation. All models with the exception of the D1 model showed relatively poor correlation between calculated and measured values with correlation coefficients $<0.4$, while the D1 model yielded a healthy correlation coefficient of 0.93 . Models H, A, BC, and $\mathrm{G}$ had unacceptable values of $N S E<0$. Based on the values of $R M S E$, the D1 model was the best performing model with an RMSE of $0.52 \mathrm{MJ} \mathrm{m}^{-2}$ day $^{-1}$ followed by the $\mathrm{H}$ and $\mathrm{D} 2$ models. Figures 6 and 7 corroborate the analysis for the year 2008 and similar to 2007, and the superior performance of the D1 model is evident.

For the validation year 2009, overall, the values of $M B E$ and $M P E$ were comparatively higher in this year than in the previous three years. All the models except the G model, on average, underestimated the monthly average daily global horizontal irradiation. Across all models, NSE $>0$ but relatively low. Based on the values of RMSE, the D1, $\mathrm{H}$, and HS models performed similarly with values of $1.16,1.17$, and $1.17 \mathrm{MJ} \mathrm{m}^{-2}$ day ${ }^{-1}$, respectively. Figures 6 and 7 corroborate the analysis for the year 2009 but are more challenging than in previous years of discerning the top performers.

For the validation year 2010, overall, the values of $M B E, M P E$, and RMSE were comparatively higher than in the previous four years. As opposed to the previous three years, all the models, on average, overestimated the monthly average daily global horizontal irradiation. The D1 model showed a significantly higher correlation coefficient of 0.93 compared to the other models. All the models had NSE $>0$. Based on RMSE, the D1 model was the best performing model with an RMSE of $0.76 \mathrm{MJ} \mathrm{m}^{-2} \mathrm{day}^{-1}$ followed by the D2 model. Figures 6 and 7 

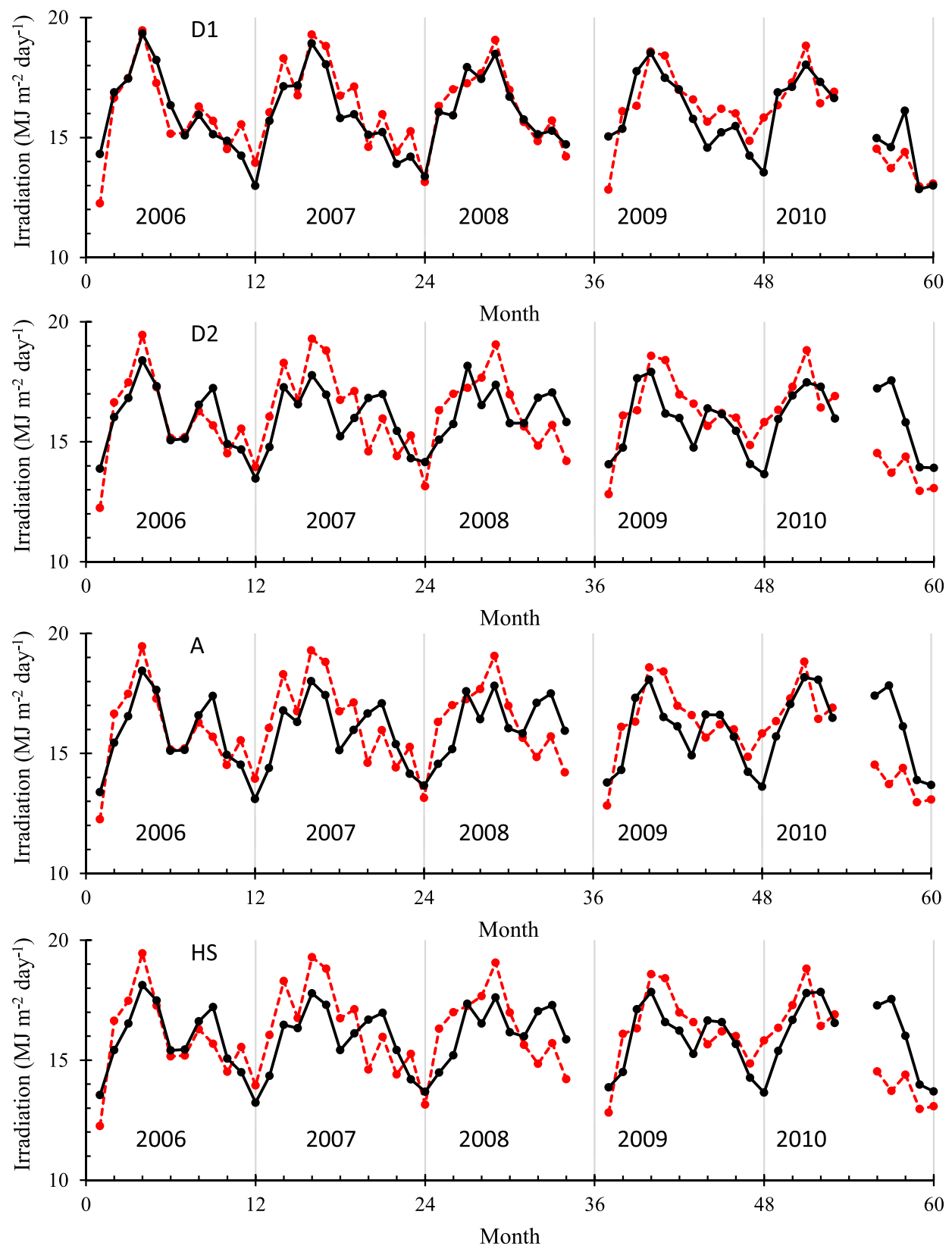

FIG. 6. Graphs of calculated (solid line) and measured (dashed line) monthly average daily global solar irradiation against month for the D1, D2, HS, and A models over the consecutive validation years 2006-2010.

corroborate the analysis for the year 2010. The superior performance of the D1 model over the whole year is evident.

The analysis of the performance of the seven models in individual years has been completed.

\section{The five yearly validation periods considered collectively}

Considering the five one-year validation periods collectively allows one to determine the performance of the models in a given month over the yearly short term and the most suitable models for both yearly and average year bases. The following analyses address these matters.

The monthly performance of the models determines the best performing model for every month in spite of the monthly and interannual variation of global horizontal irradiation. 

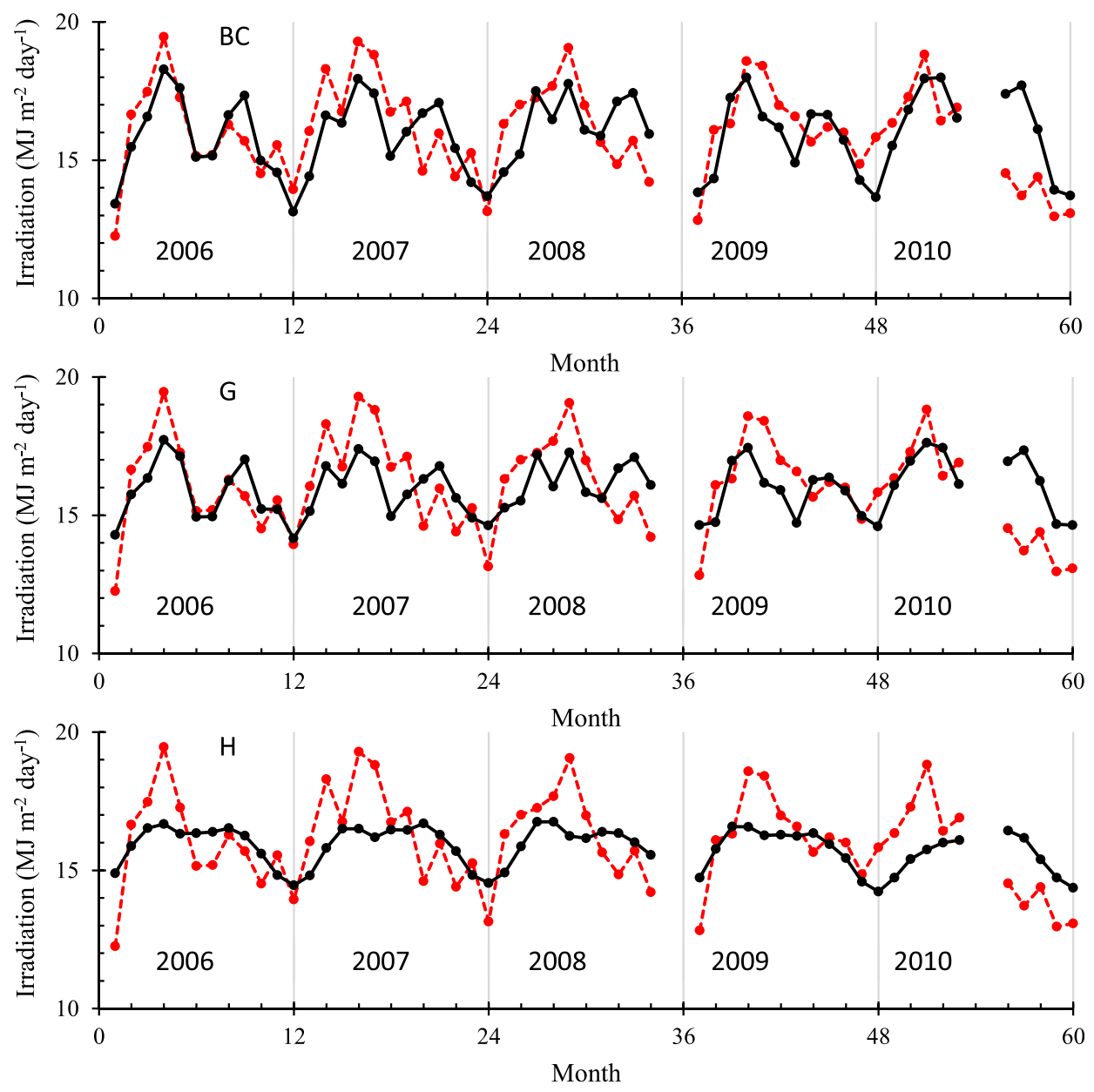

FIG. 7. Graphs of calculated (solid line) and measured (dashed line) monthly average daily global solar irradiation against month for the BC, G, and $\mathrm{H}$ models over the consecutive validation years 2006-2010.

Table IV shows the RMSE values for each model by comparing their calculated and measured monthly average daily global horizontal irradiation for each month over the five single validation years 2006-2010 together with the best performing model. The D1 model was the best performing model for nine months, the D2 model for two months, and the G, A, and HS models for one month each. For every month, the D1 model performed consistently well and it was the only model for which RMSE values were less than $1 \mathrm{MJ} \mathrm{m}^{-2} \mathrm{day}^{-1}$ for ten months and with all values less than $1.5 \mathrm{MJ} \mathrm{m}^{-2} \mathrm{day}^{-1}$. The performance of the other models varied widely over the months. For example, the A and BC models were first and second in March but were the worst performers in September and August, respectively.

Hence, from year to year, even though global horizontal irradiation in a given month varies due to varying weather conditions, the D1 model shows overall best stability in its response to these changes in the short term.

The overall performance of the models to estimate monthly average daily global horizontal irradiation in the short term can be determined by calculating the statistical test parameters for all of the calculated and measured monthly average daily global horizontal irradiation for the five years collectively, i.e., fifty-six pairs of calculated and measured data, recalling that there were no global horizontal irradiation data for four months during the five validation years. The calculated statistical test parameters are given in Table V. Notice the designations $R M S E_{S T}$ and $R M S E_{L T}$. The former refers to the values of RMSE for short term (subscript 'ST') or yearly time frames. The latter refers to the values of RMSE for long term (subscript 'LT') or an 
TABLE IV. RMSE values (MJ m ${ }^{-2} \mathrm{day}^{-1}$ ) for the seven models for each month with the lowest values emboldened and the best performing model displayed.

\begin{tabular}{lcccccccc}
\hline \hline & HS & $\mathrm{A}$ & $\mathrm{BC}$ & $\mathrm{G}$ & $\mathrm{H}$ & $\mathrm{D} 1$ & $\mathrm{D} 2$ & Best model \\
\hline Jan & 1.41 & 1.30 & 1.33 & 1.37 & 1.83 & 1.39 & $\mathbf{1 . 2 2}$ & $\mathrm{D} 2$ \\
Feb & 1.48 & 1.44 & 1.46 & 1.20 & 1.53 & $\mathbf{0 . 7 9}$ & 0.99 & $\mathrm{D} 1$ \\
Mar & 0.68 & $\mathbf{0 . 6 3}$ & 0.65 & 0.80 & 1.46 & 0.70 & 0.90 & $\mathrm{~A}$ \\
Apr & 1.26 & 1.20 & 1.22 & 1.53 & 2.03 & $\mathbf{0 . 4 4}$ & 1.09 & $\mathrm{D} 1$ \\
May & 1.25 & 1.21 & 1.21 & 1.57 & 2.05 & $\mathbf{0 . 7 4}$ & 1.55 & $\mathrm{D} 1$ \\
Jun & 0.87 & 1.03 & 1.00 & 1.20 & 0.81 & $\mathbf{0 . 7 7}$ & 1.09 & D1 \\
July & 0.86 & 1.02 & 1.01 & 1.16 & 0.80 & $\mathbf{0 . 7 1}$ & 1.07 & D1 \\
Aug & 1.89 & 1.93 & 1.94 & 1.58 & 1.47 & $\mathbf{0 . 6 1}$ & 1.83 & D1 \\
Sept & 2.03 & 2.21 & 2.15 & 1.88 & 1.15 & $\mathbf{0 . 7 5}$ & 2.00 & D1 \\
Oct & 1.17 & 1.20 & 1.21 & 1.34 & 1.09 & $\mathbf{0 . 8 8}$ & 1.11 & D1 \\
Nov & 0.95 & 0.94 & 0.92 & $\mathbf{0 . 8 9}$ & 0.99 & $\mathbf{0 . 8 9}$ & $\mathbf{0 . 8 9}$ & D1, D2, G \\
Dec & $\mathbf{1 . 2 2}$ & 1.25 & 1.23 & 1.25 & 1.27 & 1.24 & 1.29 & HS \\
\hline \hline
\end{tabular}

average year which are contained in Table III for the validation period 2006-2010 but is reproduced in Table $\mathrm{V}$ for ease of reference.

The statistical test parameters were acceptable. All the models on average, underestimated the monthly average daily global horizontal irradiation. The D1 model showed comparatively superior $r$ and NSE. The D1 model was the best performer with an RMSE $E_{S T}$ of $0.86 \mathrm{MJ}$ $\mathrm{m}^{-2}$ day $^{-1}$ followed by the D2 and HS models which had close RMSE values of 1.31 and $1.33 \mathrm{MJ} \mathrm{m}^{-2} \mathrm{day}^{-1}$, respectively, which were comparable to the $\mathrm{A}, \mathrm{BC}$, and $\mathrm{G}$ models which had equal RMSEs of $1.36 \mathrm{MJ} \mathrm{m}^{-2} \mathrm{day}^{-1}$. The $\mathrm{H}$ model had the highest RMSE. Hence, for predicting monthly average daily global horizontal irradiation over the yearly short terms, the most accurate model is the D1 model followed by the D2 and HS models.

To further elucidate the performance of the models, Fig. 8 shows 1:1 lines and scatter plots of the fifty-six pairs of calculated versus measured monthly average daily global horizontal irradiation for the years 2006 to 2010 collectively from the seven models D1, D2, HS, A, BC, G, and $\mathrm{H}$, respectively. The superior performance of the D1 model is evident by its overall smallest spread of plotted points about its 1:1 line as reflected in its comparatively lowest $R M S E_{S T}$. The larger number of points below, and their deviation from the 1:1 line, resulted in the negative value of $M B E$ which also applied to all the models. The D2, HS, A, BC, and G models showed comparable performances and this is also reflected in Table V. The H model shows overall larger spread of plotted points about its 1:1 line particular below $14 \mathrm{MJ} \mathrm{m}^{-2} \mathrm{day}^{-1}$ and above $18 \mathrm{MJ} \mathrm{m}^{-2} \mathrm{day}^{-1}$ of measured irradiation.

TABLE V. Statistical test parameters for the seven models by comparing fifty-six pairs of calculated and measured monthly average daily global horizontal irradiation from the years 2006 to 2010. MBE and RMSE have units of MJ $\mathrm{m}^{-2}$ day $^{-1}$. The lowest values of $R M S E$ are emboldened for the best model.

\begin{tabular}{lccccccc}
\hline \hline & $\mathrm{HS}$ & $\mathrm{A}$ & $\mathrm{BC}$ & $\mathrm{G}$ & $\mathrm{H}$ & $\mathrm{D} 1$ & $\mathrm{D} 2$ \\
\hline$M B E$ & -0.10 & -0.08 & -0.09 & -0.07 & -0.24 & -0.13 & -0.08 \\
$M P E$ & -0.08 & 0.04 & 0.02 & 0.32 & -0.60 & -0.59 & 0.09 \\
$R M S E_{S T}$ & 1.33 & 1.36 & 1.36 & 1.36 & 1.46 & $\mathbf{0 . 8 6}$ & 1.31 \\
$r$ & 0.64 & 0.64 & 0.63 & 0.61 & 0.55 & 0.87 & 0.65 \\
$N S E$ & 0.39 & 0.36 & 0.37 & 0.36 & 0.27 & 0.75 & 0.41 \\
$R M S E_{L T}$ & 0.94 & 0.97 & 0.97 & 0.97 & 0.97 & $\mathbf{0 . 5 1}$ & 0.91 \\
$\left\langle R M S E_{L T}, R M S E_{S T}\right\rangle$ & 1.14 & 1.17 & 1.16 & 1.16 & 1.22 & $\mathbf{0 . 6 8}$ & 1.11 \\
\hline \hline
\end{tabular}



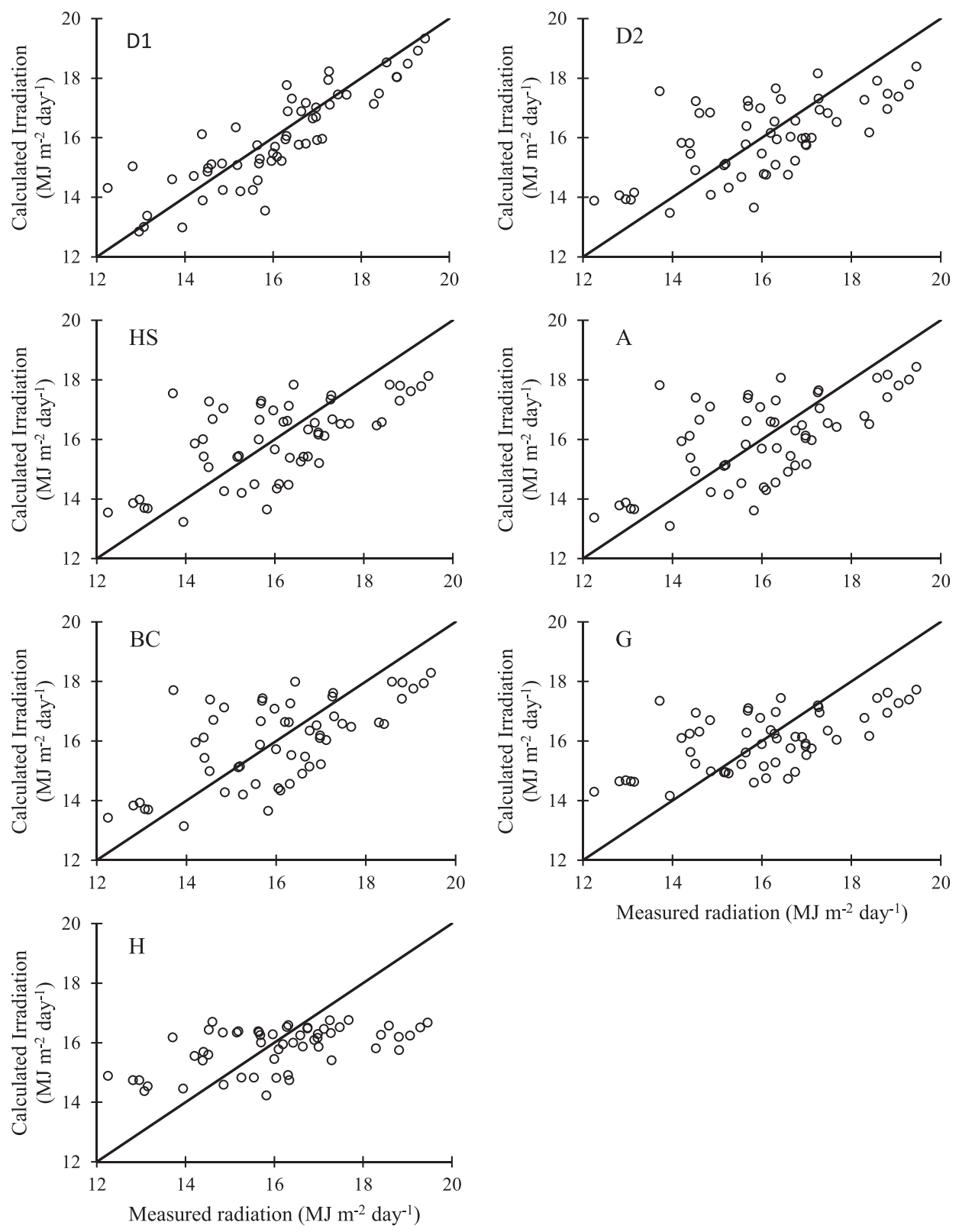

FIG. 8. 1:1 lines and scatter plots of calculated versus measured monthly average daily global solar irradiation for the years 2006-2010 collectively from the seven models D1, D2, HS, A, BC, G, and H, respectively.

By considering $\left\langle R M S E_{L T}, R M S E_{S T}\right\rangle$, the model most appropriate for use in Trinidad to estimate monthly average daily global horizontal irradiation on yearly and average year bases collectively is the D1 model with a value of $\left\langle R M S E_{L T}, R M S E_{S T}\right\rangle=0.68 \mathrm{MJ} \mathrm{m}^{-2} \mathrm{day}^{-1}$ which is approximately $39 \%$ less than that of its nearest neighbor which is the D2 model with an $\left\langle R M S E_{L T}, R M S E_{S T}\right\rangle$ of $1.11 \mathrm{MJ} \mathrm{m}^{-2} \mathrm{day}^{-1}$.

\section{CONCLUSION}

In this study, a recently developed model to predict monthly average hourly global horizontal irradiation from ambient hourly temperature only, has been extended to estimate monthly average daily horizontal irradiation and a modified form of the Hargreaves-Samani model has also been developed. These two models and five existing temperature-based models due to 
Hargreaves and Samani, Allen, Bristow and Campbell, Goodin et al., and Hassan et al. were evaluated for applicability in the region. The models were calibrated and validated using datasets 2001-2005 and 2006-2010, respectively, and were assessed statistically for performance in an average year and yearly periods by determining the mean bias error, mean percentage error, root mean square error, correlation coefficient, and Nash-Sutcliffe efficiency between the calculated and measured monthly average daily global horizontal irradiation. The newly developed temperature-based model was the best performing model. For an average year, yearly periods, and average and yearly periods collectively, the newly developed temperature-based model yielded root mean square errors of $0.51,0.86$, and $0.68 \mathrm{MJ} \mathrm{m}^{-2}$ day ${ }^{-1}$, respectively. Similarly, the modified Hargreaves-Samani model was the next best performer with root mean square errors of $0.91,1.31$, and $1.11 \mathrm{MJ} \mathrm{m}^{-2} \mathrm{day}^{-1}$, respectively, and is thus a valid and reliable derivative of the Hargreaves-Samani model. In terms of the type of temperature input, the model based on hourly temperature was superior to the models based on the diurnal temperature range (modified Hargreaves-Samani, Hargreaves-Samani, Allen, Bristow and Campbell, and Goodin et al.) which in turn were superior to the model based on diurnal average temperature (Hassan et al.). Its superior predictive accuracy; independence of extraterrestrial solar irradiation, astronomical and geographical factors, and its provision of both monthly average daily and hourly global horizontal irradiation, make the newly developed model ideally suitable for use in Trinidad and for deployment in other territories with similar climatic conditions, particularly where no global horizontal irradiation data is available. Moreover, the model may prove to be applicable in other territories that have utilized the well-established models in this study.

\section{ACKNOWLEDGMENTS}

The author recognizes the invaluable contribution of the Trinidad and Tobago Meteorological Services for providing the data used in this study and the support at the Center for Optoelectronics Research.

${ }^{1}$ T. Markvart, A. Fragaki, and J. N. Ross, Sol. Energy 80, 46 (2006).

${ }^{2}$ L. Martin, L. F. Zarzalejo, J. Polo, A. Navarro, R. Marchante, and M. Cony, Sol. Energy 84, 1772 (2010).

${ }^{3}$ R. De Jong and D. W. Stewart, Can. J. Plant Sci. 73, 509 (1993).

${ }^{4}$ T. Catalina, J. Virgone, and E. Blanco, Energy Build. 40, 1825 (2008).

${ }^{5}$ M. La Gennusa, A. Nucara, M. Pietrafesa, and G. Rizzo, Sol. Energy 81, 594 (2007).

${ }^{6}$ K. De Souza and R. Andrews, J. Renewable Sustainable Energy 7, 013132 (2015).

${ }^{7}$ K. De Souza, J. Renewable Sustainable Energy 10, 033701 (2018).

${ }^{8}$ A. Whillier, Arch. Meteorol. Geophys. Bioclimatol. B 7, 197 (1956).

${ }^{9}$ B. Y. H. Liu and R. C. Jordan, Sol. Energy 4, 1 (1960).

${ }^{10}$ M. Collares-Pereira and A. Rabl, Sol. Energy 22, 155 (1979).

${ }^{11}$ C. Gueymard, J. Sol. Energy Eng., Trans. ASME 108, 320 (1986).

${ }^{12}$ T. A. Newell, Sol. Energy 31, 339 (1983).

${ }^{13}$ J. C. Jain, Sol. Wind Technol. 1, 123 (1984).

${ }^{14}$ G. H. Hargreaves and Z. A. Samani, J. Irrig. Drain Eng., ASCE 108, 223 (1982).

${ }^{15}$ K. I. Bristow and G. S. Campbell, Agric. Forest Meteorol. 31, 159 (1984).

${ }^{16}$ J. G. Annandale, N. Z. Jovanic, N. Benade, and R. G. Allen, Irrig. Sci. 21, 57 (2002).

${ }^{17}$ R. G. Allen, J. Hydrol. Eng. 2, 56 (1997).

${ }^{18}$ D. G. Goodin, J. M. S. Hutchinson, R. L. Vanderlip, and M. C. Knapp, J. Agron. 91, 845 (1999).

${ }^{19}$ G. E. Hassan, M. E. Youssef, Z. E. Mohamed, M. A. Ali, and A. A. Hanafy, Appl. Energy 179, 437 (2016).

${ }^{20}$ J. A. Duffie and W. A. Beckman, Solar Engineering of Thermal Processes (John Wiley \& Sons, New York, 2013).

${ }^{21}$ P. I. Cooper, Sol. Energy 12, 3 (1969).

${ }^{22}$ Z. Sen, Sol. Energy 63, 39 (1998).

${ }^{23}$ A. Angström, Q. J. R. Meterol. Soc. 50, 121 (1924).

${ }^{24}$ J. A. Prescott, Trans. R. Soc. South Australia 64, 114 (1940).

${ }^{25}$ F. Castellvi, Open Atmos. Sci. J. 2, 185 (2008).

${ }^{26}$ G. H. Hargreaves, "Simplified coefficients for estimating monthly solar radiation in North America and Europe," Utah State University, Logan, Utah, 1994. 